\begin{tabular}{|c|c|}
\hline Title & Recovery of protein-losing enteropathy after living-donor lobar lung transplantation in primary pulmonary hypertension \\
\hline Author(s) & $\begin{array}{l}\text { Ohira, Hiroshi; T sujino, Ichizo; Sakaue, Shinji; Ikeda, Dai suke; Itoh, Naofumi; Kamigaki, Mitsunori; Ishimaru, Shinji; } \\
\text { Date, Hiroshi; Sano, Y oshifumi; Shimizu, Nobuy oshi; Nishimura, Masaharu }\end{array}$ \\
\hline Citation & $\begin{array}{l}\text { The Journal of heart and lung transplantation, 25(4), 486-488 } \\
\text { https://doi.org/10.1016/.healun.2005.08.016 }\end{array}$ \\
\hline Issue Date & 2006-04 \\
\hline Doc URL & http:/hdl .handle.net/2115/8424 \\
\hline Rights & International Society for Heart and Lung T ransplantation \\
\hline Type & article (author version) \\
\hline File Information & JHLT_25(4)_486.pdf \\
\hline
\end{tabular}

Instructions for use 


\section{Recovery of Protein-losing Enteropathy After Living-donor Lobar Lung Transplantation in Primary Pulmonary Hypertension}

Hiroshi Ohira, Ichizo Tsujino, Shinji Sakaue, Daisuke Ikeda, Naofumi Itoh, Mitsunori Kamigaki, Shinji Ishimaru, Hiroshi Date, Yoshifumi Sano, Nobuyoshi Shimizu and Masaharu Nishimura

\footnotetext{
Abstract

The authors encountered a 43-year-old woman with primary pulmonary hypertension (PPH) and refractory protein-losing enteropathy (PLE). The patient underwent living-donor lobar lung transplantation (LDLLT), which led to remarkable improvement in both pulmonary hypertension and PLE. Although there have been no reports, to our knowledge, which have demonstrated PLE as a complication of PPH, the present case indicated that PLE could certainly complicate PPH. Additionally, and more importantly, hypo-proteinemia due to PLE should not necessarily be an exclusion criterion for lung transplantation when PPH is involved, because it could markedly improve after lung transplantation.
} 


\section{Introduction}

Protein-losing enteropathy (PLE) is characterized by an excessive protein loss into the gastrointestinal tract. This condition is associated not only with gastrointestinal disorders, but also with heart disease, collagen disease, and several other generalized disorders. ${ }^{1}$ Among such extra-gastrointestinal diseases, constrictive pericarditis or longstanding congestive heart failure are known to cause PLE, particularly when they complicate right-sided heart failure. ${ }^{2,3}$ However, PLE, secondary to pulmonary hypertension (PH), has rarely been reported thus far, although PH often provokes severe right-sided heart failure. In addition, therapeutic outcome for lung transplantation on PLE performed on patients with PH is also unknown.

In the present report, we document a case of primary pulmonary hypertension (PPH) complicated by PLE, and describe a clinical process concerning which living-donor lung transplantation (LDLLT) dramatically improved PLE as well as pulmonary hemodynamics. 


\section{Case report}

In June 1998, a 43-year-old woman experienced dyspnea on exertion and was referred to our hospital in 1999. In July 1999, the patient underwent right heart catheterization and was diagnosed as having PPH. Oral Beraprost and Warfarin was started at this time, but her symptoms gradually worsened, and continuous intravenous prostacyclin therapy was initiated in August 2000. After a stable state lasting over a two-year period, she experienced symptoms suggesting right-sided heart failure and was again admitted to our hospital in October 2003. Among the blood test findings on admission, serum levels of total protein and albumin were found to have remarkably declined to $4.1 \mathrm{~g} / \mathrm{dL}$ and $2.2 \mathrm{~g} / \mathrm{dL}$, respectively. Although we initially suspected the influence of systemic water excess secondary to right-sided heart failure, albumin infusion of 12.5 to $25 \mathrm{~g}$ daily did not lead to sufficient improvement in those levels. In addition, upper gastrointestinal endoscopy showed edematous changes of duodenal mucosa, which led us to suspect PLE as a cause of refractory hypo-protein and hypo-albuminemia. To further confirm the possibility of PLE, we performed gastrointestinal scintigraphy using intravenous ${ }^{99 \mathrm{~m}}$ Tc-human serum albumin (HSA) and found significant leakage of ${ }^{99 \mathrm{~m}} \mathrm{Tc}-\mathrm{HSA}$ into the intestinal lumen (Fig 1A). We thus diagnosed this case as diagnosis PLE associated with PPH. 
Although medical therapy improved right-sided heart failure and also the levels of serum protein and albumin rose to $5.1 \mathrm{~g} / \mathrm{dl}$ and $3.4 \mathrm{~g} / \mathrm{dl}$, respectively, use of large dosage of diuretics; Furosemid $480 \mathrm{mg}$ daily and continuous injection of Mannitol, and albumin infusions (25 g daily) were required. Consequently, it was considered to be hard to maintain such medical therapy. In November, the patient was referred to Okayama University Hospital because of the availability of a possible candidate for a living-donor lobar lung transplantation (LDLLT). She and her family eventually agreed to the operation. In December 2003, she underwent an LDLLT, receiving a right lower lobe from her son and a left lower lobe from her husband. After the LDLLT, her pulmonary hemodynamics dramatically improved and the serum levels for total protein and albumin significantly increased (See Table). In addition, other medical treatment including diuretics and albumin infusion became unnecessary postoperatively.

In July 2004, she underwent a second ${ }^{99 \mathrm{~m}}$ Tc-HSA scintigram that showed complete disappearance of intestinal leakage of ${ }^{99 \mathrm{~m}}$ Tc-HSA into the gastrointestinal tract (Fig 1B). 


\section{Discussion}

The present report documents the case of a 43-year-old woman with PPH complicated by PLE that was confirmed by ${ }^{99 \mathrm{~m}} \mathrm{Tc}-\mathrm{HSA}$ scintigraphy. In our search of the literature, this is the first case report that demonstrates PLE as a complication of PPH and describes a dramatic recovery from PLE as well as pulmonary hemodynamics based on an LDLLT.

Before the LDLLT, we initially considered several possible causes of PLE other than PPH. For example, any gastrointestinal or collagen disease, ${ }^{4}$ or constrictive pericarditis ${ }^{3}$ might have provoked PLE. However, none of the patient's symptoms, blood data, or findings related to upper gastrointestinal endoscopy suggested the presence of gastrointestinal or collagen diseases. In addition, constrictive pericarditis was also ruled out based on an ultrasound cardiogram, chest computed tomography, and right heart catheterization. We thus suspected that the PLE, observed in the present case, was secondary to $\mathrm{PPH}$.

Low serum levels for total protein and albumin are thought to be a risk factor related to poor postoperative outcomes in major surgeries. ${ }^{5}$ Indeed, we did not consider in November 2003 that LDLLT was an indication for the present case because total protein and albumin levels were as low as $4.1 \mathrm{~g} / \mathrm{dl}$ and $2.2 \mathrm{~g} / \mathrm{dl}$, respectively. However, the LDLLT resulted in marked improvement 
of those values in the present case, which meant that low levels of serum protein and albumin should not necessarily be exclusion criteria for LDLLT at least in patients with PPH.

In conclusion, the present case indicated that PLE should be included as one of the extra-thoracic complications of PPH. In addition, we propose that lung transplantation should remain a therapeutic option for the patients with $\mathrm{PPH}$ even if they have refractory hypo-proteinemia secondary to PLE. 


\section{References}

1. Yamada T, Alpers DH, Laine L, Owyang C, Powell DW. Textbook of Gastroenterology. 3rd ed. Philadelphia: Lippincott Williams \& Wilkins; 1999. p. 1752-4

2. Davidson JD, Waldmann TA, Goodman DS, Gordon RS. Protein-losing gastroenteropathy in congestive heart failure. Lancet 1961;1:899-902

3. Wilkinson P, Pinto B, Senior JR. Reversible protein-losing enteropathy with intestinal lymphangiectasia secondary to chronic constrictive pericarditis. N Engl J Med 1965; 273:1178-81

4. Tsutsumi A, Sugiyama T, Matsumura R, et al. Protein losing enteropathy associated with collagen diseases. Ann Rheum Dis 1991; 50:178-81

5. Schwartz SI, Shires GT, Spencer FC, Husser WC. Principles of surgery. 5th ed. New York: McGraw-Hill Book Company; 1989. p. 637-8 


\section{Figure legend}

${ }^{99 \mathrm{~m}}$ Tc-human serum albumin (HSA) scintigraphy before (A) and after (B) living-donor lung transplantation (LDLLT)

A: ${ }^{99 \mathrm{~m}}$ Tc-HSA scintigram obtained before LDLLT: There is abnormal radio-reactivity in transverse, descending, and sigmoid colons (arrows).

B: ${ }^{99 \mathrm{~m}}$ Tc-HSA scintigram after LDLLT: Radio-reactivity indicated the leakage of ${ }^{99 \mathrm{~m}} \mathrm{Tc}-\mathrm{HSA}$ into the colon was considerably improved. 


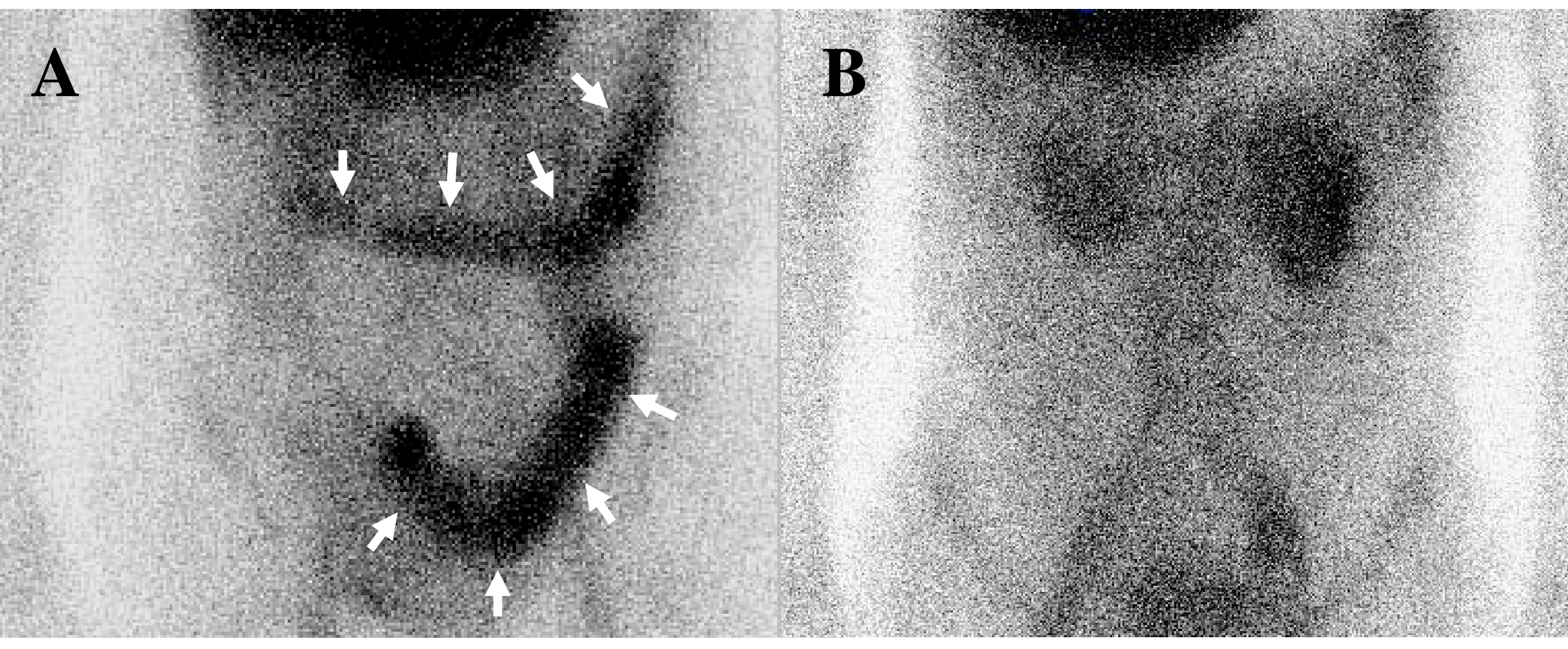


Table; Pulmonary hemodynamics and blood data before and after living-donor lung transplantation

\begin{tabular}{|c|c|c|c|c|}
\hline & \multicolumn{2}{|c|}{ Preoperative } & \multicolumn{2}{|c|}{ Postoperative } \\
\hline & 03/ October & 03/ November & 04/February & 04/December \\
\hline mRAP (mmHg) & 15 & N.D. & -1 & 0 \\
\hline RVEDP (mmHg) & 19 & N.D. & 2 & 9 \\
\hline PAP (mmHg) & $107 / 47(72)$ & N.D. & 19/6 (11) & 24/6 (13) \\
\hline mPCWP (mmHg) & 12 & N.D. & 4 & 7 \\
\hline $\mathrm{CI}\left(\mathrm{L} \cdot \min ^{-1} \cdot \mathrm{m}^{-2}\right)$ & 2.4 & N.D. & 2.5 & 2.5 \\
\hline PVR (dyne $\cdot \sec ^{-1} \cdot \mathrm{cm}^{-5}$ ) & 1237 & N.D. & 17 & 130 \\
\hline $\mathrm{TP}(\mathrm{g} / \mathrm{dl})$ & 4.1 & 5.1 & 5.8 & 6.3 \\
\hline Alb (g/dl) & 2.1 & 3.4 & 4.0 & 3.9 \\
\hline ANP (pg/ml) & 630 & 312 & 63 & N.D. \\
\hline $\mathrm{BNP}(\mathrm{pg} / \mathrm{ml})$ & 896 & 669 & 74 & 54 \\
\hline
\end{tabular}

mRAP: mean right atrial pressure, RVEDP: right ventricular end diastolic pressure, PAP:

pulmonary artery pressure, mPCWP: mean pulmonary capillary wedge pressure, CI: cardiac index, PVR: pulmonary vascular resistance, TP: total protein, Alb: albumin, ANP: atrial 
natriuretic peptide, BNP: brain natriuretic peptide, N.D.: not done. 